Check for updates

Cite this: RSC Adv., 2019, 9, 30976

\section{Encapsulation of echinomycin in cyclodextrin inclusion complexes into liposomes: in vitro anti- proliferative and anti-invasive activity in glioblastoma $\uparrow$}

Walhan Alshaer, (D) $t^{* a}$ Manar Zraikat, $i^{\mathrm{b}}$ Amer Amer, ${ }^{\mathrm{c}}$ Hamdi Nsairat, ${ }^{\mathrm{d}}$ Zainab Lafi, ${ }^{\mathrm{c}}$ Dana A. Alqudah, ${ }^{a}$ Enas Al Qadi, ${ }^{\mathrm{b}}$ Tasneem Alsheleh, ${ }^{\mathrm{b}}$ Fadwa Odeh, ${ }^{\mathrm{d}}$ Arwa Alkaraki, ${ }^{\text {ab }}$ Malek Zihlif, ${ }^{b}$ Yasser Bustanji, ${ }^{c e}$ Elias Fattal $\mathbb{D D}^{f}$ and Abdalla Awidi ${ }^{\star a g}$

Echinomycin, a DNA bis-intercalator peptide, belongs to the family of quinoxaline antibiotics. Echinomycin exhibits potent antitumor and antimicrobial activity. However, it is highly water insoluble and suffers from low bioavailability and unwanted side effects. Therefore, developing new formulations and delivery systems that can enhance echinomycin solubility and therapeutic potency is needed for further clinical application. In this study, echinomycin has been complexed into the hydrophobic cavity of $\gamma$ cyclodextrin $(\gamma C D)$ then encapsulated into PEGylated liposomes. The anti-proliferative and anti-invasive effect has been evaluated against U-87 MG glioblastoma cells. Echinomycin-in- $\gamma C D$ inclusion complexes have been characterized by phase solubility assay, TLC, and ${ }^{1} \mathrm{H}-\mathrm{NMR}$. The echinomycin-in$\gamma C D$ inclusion complexes have been loaded into liposomes using a thin film hydration method to end up with echinomycin-in- $\gamma C D$-in-liposomes. Drug-loaded liposomes were able to inhibit cell proliferation with $I_{50}$ of $1.0 \mathrm{nM}$. Moreover, echinomycin-in- $\gamma \mathrm{CD}$-in-liposomes were found to inhibit the invasion of U-87 MG cells using the spheroid gel invasion assay. In conclusion, the current work describes for the first time $\gamma C D$-echinomycin complexes and their encapsulation into PEGylated liposomes.
Received 21st July 2019

Accepted 20th September 2019

DOI: $10.1039 / c 9 r a 05636 j$

rsc.li/rsc-advances breast cancer, glioma, colon cancer, pancreatic cancer, gastric cancer, and cervical cancer. ${ }^{3-5}$ Interestingly, echinomycin can selectively kill the leukemia-initiating cells in relapsed acute myeloid leukemia (AML) without harming the normal stem cells. In 2015, echinomycin has received an orphan drug status for AML in the USA. ${ }^{6}$ The mechanism of action of echinomycin is attributed to the bis-intercalation and binding with high affinity to the 5 -CG bases of DNA, which prevent the unwinding of the double helical DNA; thus, inhibiting the replication of chromosomal DNA. ${ }^{4,7,8}$ Furthermore, it is a potent inhibitor of the hypoxia-inducible factor-1 (HIF-1) DNA-binding, a factor that controls genes necessary in tumor biology including cell growth, glycolysis, angiogenesis, metastasis, and invasion. ${ }^{7}$ Unfortunately, no significant response was observed in clinical trials conducted on patients suffering from metastatic soft tissue sarcoma, advanced breast cancer, squamous cell cervical carcinoma, advanced ovarian cancer, advanced renal carcinoma, central nervous system, and colorectal cancer due to its high dose-related toxicity. ${ }^{8-20}$ One of the most common side effects is related to echinomycin in gastrointestinal tract symptoms, including moderate to severe nausea, vomiting, and diarrhea, as well as the elevation of hepatic enzymes and a mild decrease in platelets and granulocyte counts which was lifethreading in some cases. ${ }^{\mathbf{1 1 , 2 1}}$ Accordingly, in all clinical trials, $\dagger$ Electronic supplementary information (ESI) available. See DOI: 10.1039/c9ra05636j

$\ddagger$ These authors contributed equally to this work.

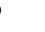


no dose escalation was possible to achieve a significant clinical response. Moreover, echinomycin is highly water insoluble and precipitates when added to water which complicates the formulation of proper dosage forms thereby suffering from low bioavailability. The available solvents for echinomycin are clinically unacceptable. Therefore, there is a need for new formulations and delivery systems that can enhance solubility and therapeutic potency of echinomycin.

Glioblastoma (GBM) is a common and aggressive type of malignant brain tumors. ${ }^{22}$ GBM accounts for $16 \%$ of all primal cases of brain tumors. It is a fatal and non-curable disease, with only less than $5 \%$ of patients that survive after 5 years of diagnosis. ${ }^{22,23}$ Different treatments are in use for GMB including surgery, radiation, chemotherapy, and immunotherapy. ${ }^{24}$ Nevertheless, these therapies don't bear a higher survival rate in GBM patients due to the aggressive nature of GBM that invades normal cells of the central nervous system and the protection advantage by the neurovascular niche. ${ }^{25}$

Liposomes have unique properties that expanded the scope of pharmacokinetic and pharmacodynamics of insoluble drugs. ${ }^{26,27}$ Liposomes are widely used in clinics as drug delivery systems. ${ }^{28}$ Liposomes have sophisticated properties including the biocompatibility, low toxicity, biodegradability, and the targeting capability. ${ }^{29}$ Due to its tiny size, liposomes have the ability to penetrate leaky blood vessels of tumor cell by passive targeting mechanism usually referred to enhanced permeability and retention effect. ${ }^{30}$ Additionally, Stealth ${ }^{\circledR}$ liposomes coated with hydrophilic polymers such as polyethylene glycol (PEG) showed prolong blood halflife by masking their detection and destruction by the mononuclear phagocyte system (MPS). ${ }^{31}$

Cyclodextrins (CDs) are biocompatible and water-soluble cyclic oligosaccharides. CDs consist of the lipophilic crater and hydrophilic outer exterior. These novel features of CDs can enhance the physiochemical properties of water-insoluble drugs. The natural $\alpha-, \beta$ - and $\gamma$-cyclodextrin consist of 6,7 , and 8 glucopyranose units, respectively. ${ }^{32}$ Although CDs are valuable solubilizers of hydrophobic drugs, the complex formation of gust drug and the host CD cavity is weak and the drug suffers dissociation after administration in vivo in which the blood components can displace the included drug. Moreover, drug-in-CD inclusion is challenged by rapid renal clearance, renal toxicity, and interaction with the cellular membrane components. Therefore, combining the dual models of drug-inCD-in-liposomes can augment the fate of hydrophobic drugs in vivo. ${ }^{32}$ In the current work, the echinomycin-in- $\gamma$ CD-inliposomes formulation has been developed. First, echinomycin (Fig. 1A) has been complexed into $\gamma \mathrm{CD}$ (Fig. 1B) and the echinomycin-in- $\gamma \mathrm{CD}$ complex inclusion has been characterized by phase solubility assay TLC, and ${ }^{1} \mathrm{H}-\mathrm{NMR}$. Then, the echinomycin-in- $\gamma \mathrm{CD}$ inclusion has been loaded into the aqueous core of PEGylated liposomes using thin-film hydration method. The resulting echinomycin-in- $\gamma$ CD-in-liposomes have been characterized for the encapsulation efficacy, size, charge, uptake, and the anti-proliferative and anti-invasive activity against U-87 MG glioblastoma cells.

\section{Materials and methods}

\subsection{Chemicals}

Echinomycin ( $\mathrm{N}$-(2-quinoxalinylcarbonyl)-O-[ $\mathrm{N}$-(2-quinoxalinylcarbonyl)-D-seryl-L-alanyl-3-mercapto- $N, S$-dimethylcysteinyl- $N$-methyl-L-valyl]-D-seryl-L-alanyl- $N$-methylcysteinyl- $N$ methyl L-valine (81)-lactone cyclic (37)-thioester) obtained from TOCRIS® bioscience (Bristol, UK). The lipids; DPPC (1,2-dihexadecanoyl-sn-glycero-3-phosphocholine), DSPEPEG2000 (1,2-distearoyl-sn-glycero-3-phosphoethanolamine$N$-[methoxy(polyethyleneglycol)-2000]). 1,2-Dioleoyl-sn-glycero-3-phosphoethanolamine $-\mathrm{N}$-(lissamine rhodamine $\mathrm{B}$ sulfonyl) (Lissamine) (Rho-PE), and cholesterol were purchased from Avanti Polar Lipids (Alabaster, USA). $\gamma$ cyclodextrin was purchased from Sigma-Aldrich (USA). Other chemicals were obtained from different sources and were used as received.

\subsection{Phase solubility and binding constant of echinomycin with $\gamma \mathbf{C D}$}

Phase solubility analysis was performed according to the method reported by Higuchi. ${ }^{33}$ A constant amount of echinomycin $(55 \mu \mathrm{M})$ was added into $3 \mathrm{~mL}$ of $\gamma \mathrm{CD}$ aqueous solutions with various concentrations $(0.025-0.22 \mathrm{mM})$. Then all samples were mixed on a shaker at $25{ }^{\circ} \mathrm{C}$ for $24 \mathrm{~h}$. After the equilibrium was reached, the mixtures were centrifuged for $5 \mathrm{~min}$ at $1000 \mathrm{rpm}$. The concentration of echinomycin in the supernatant was determined by a UV Nanodrop spectroscopy (Thermo Scientific) using a calibration curve. The binding constant $\left(K_{1: 1}\right)$ and complexation efficiency (CE) were analyzed using equations were analyzed using the equations:

$$
\begin{gathered}
K_{1: 1}=\operatorname{slope} / S_{0}(1-\text { slope })=[\text { Ech }-\gamma \mathrm{CD}] /[\mathrm{Ech}][\gamma \mathrm{CD}] \\
\mathrm{CE}=[\mathrm{D}-\mathrm{CD}] /[\mathrm{CD}]=S_{0} K_{1: 1}=\operatorname{slope} /(1-\text { slope })
\end{gathered}
$$

where: $S_{0}$ is drug solubility without cyclodextrin (i.e. drug intrinsic solubility in water) and the slope is the slope of the linear part of the phase solubility diagram. ${ }^{34}$

\subsection{Determination of stoichiometry of echinomycin with $\gamma$ CD using Benesi-Hildebrand method}

A constant amount of echinomycin $(35 \mu \mathrm{M})$ was added into $3 \mathrm{~mL}$ of $\gamma \mathrm{CD}$ polymer aqueous solutions with various concentrations (0.0125-0.175 mM). Then all samples were mixed on a shaker at $25{ }^{\circ} \mathrm{C}$ for $24 \mathrm{~h}$. Then the mixtures were centrifuged for $5 \mathrm{~min}$ at $1000 \mathrm{rpm}$. The absorbance of echinomycin of each supernatant was scanned by a UV Nanodrop spectroscopy (Thermo Scientific TM Nanodrop 2000 and 200C) using the wavelengths 290-300 Benesi-Hildebrand correlation between 1/ $[\gamma \mathrm{CD}]$ and $1 /[\gamma \mathrm{CD}]^{2}$ vs. $1 /\left(A-A_{0}\right)$ were plotted.

\subsection{Characterization of the echinomycin-in- $\gamma$ CD complex by ${ }^{1}$ H-NMR spectroscopy}

The complex was prepared by solvent evaporation encapsulation technique. A 1:2 drug to the $\gamma \mathrm{CD}$ ratio $(0.22 \mu \mathrm{mol}$ of 
A

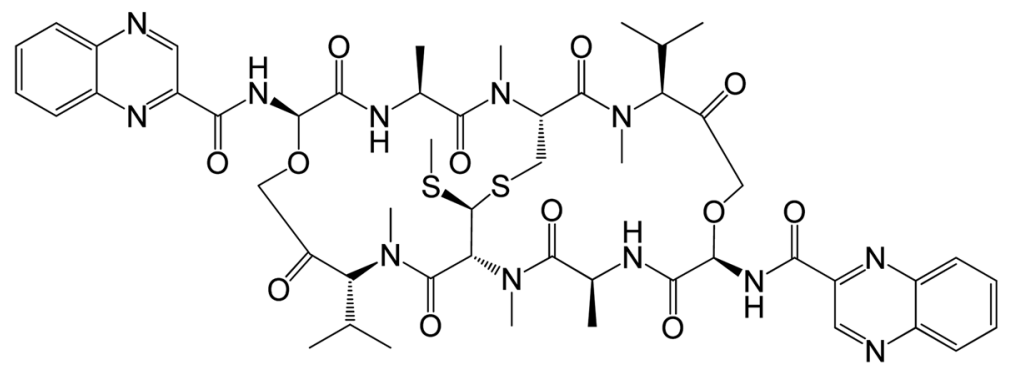

B

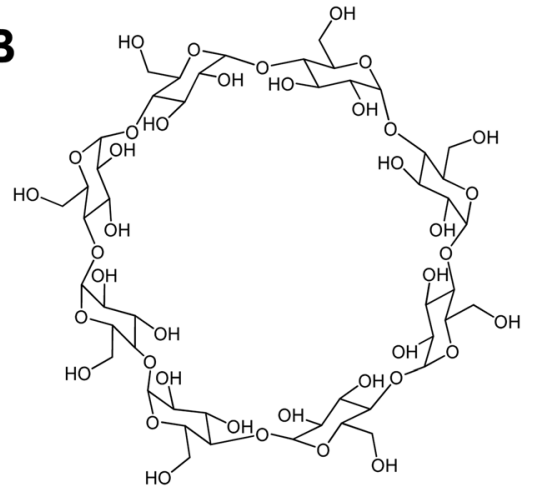

Fig. 1 The chemical structure of echinomycin (A) and $\gamma C D(B)$.

echinomycin, $0.24 \mathrm{mg}$ and $0.44 \mu \mathrm{mol}$ of $\gamma \mathrm{CD}, 0.57 \mathrm{mg}$ ) were dissolved separately in $1 \mathrm{~mL}$ ethanol and $2 \mathrm{~mL}$ deionized water, respectively. The solution was then mixed on a shaker at $280 \mathrm{rpm}$ at room temperature for $24 \mathrm{~h}$. The solution was dried completely at $50{ }^{\circ} \mathrm{C}$ under vacuum. ${ }^{35}$ The ${ }^{1} \mathrm{H}$-NMR analysis was performed using Bruker Avance III $500 \mathrm{mHz}$ instrument (Bruker BioSpin, Switzerland).

\subsection{Echinomycin- $\gamma \mathrm{CD}$ inclusion complex preparation}

The inclusion of echinomycin into $\gamma \mathrm{CD}$ was performed using dispersion/co-evaporated dispersion method. A stock of echinomycin was prepared by dissolving $1 \mathrm{mg}$ of echinomycin in $1 \mathrm{~mL}$ of chloroform to achieve $1 \mathrm{mg} \mathrm{mL}^{-1}$ final concentration. A stock solutions $\gamma \mathrm{CD}$ was prepared by dissolving $1 \mathrm{mg}$ of $\gamma \mathrm{CD}$ powder in $1 \mathrm{~mL}$ PBS (pH 7.4) to achieve $1 \mathrm{mg} \mathrm{mL} \mathrm{mL}^{-1}$ final
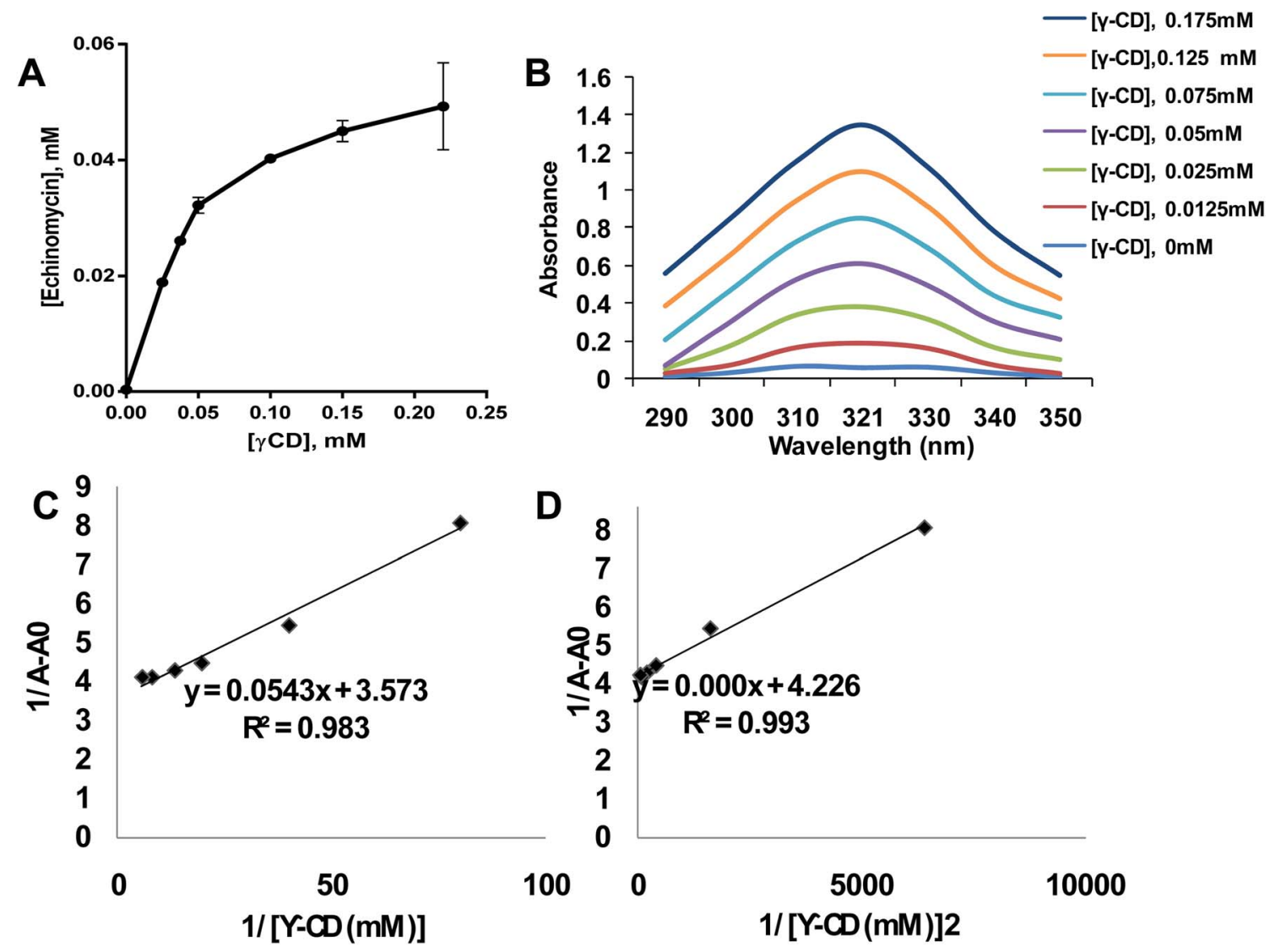

Fig. 2 Formation of echinomycin-in- $\gamma C D$ inclusion complexes. (A) Phase solubility diagram of echinomycin 0.055 mM concentration vs. different $\gamma C D$ concentration from $0.025-0.22 \mathrm{mM}(n=3)$. (B) Scanning for absorbance of Echi- $\gamma C D$ from $290-350 \mathrm{~nm}$ is showing an increase in UV spectra by increasing the concentration of $\gamma C D$. (C) Echinomycin $0.035 \mathrm{mM}$ concentration $1 /\left(A-A_{0}\right) v s$. $1 /[\gamma C D]$ of different $\gamma C D$ concentration from $0.025-0.22 \mathrm{mM}(n=3)$. (D) Echinomycin $0.023 \mathrm{mM}$ concentration $1 /\left(A-A_{0}\right)$ vs. $1 /[\gamma C D]^{2}$ of different $\gamma C D$ concentration from $0.012-0.1 \mathrm{mM}(n=3)$. 
concentration. The echinomycin-in- $\gamma \mathrm{CD}$ inclusion was prepared by dropwise addition of $100 \mu \mathrm{L}$ of echinomycin dissolved in chloroform into $235 \mu \mathrm{L}$ of the $\gamma \mathrm{CD}$ solution to get $1: 2$ molar ration of echinomycin- $\gamma \mathrm{CD}$. The complex solution was then stirred for $1 \mathrm{~h}$ at room temperature. Further, the chloroform was evaporated under vacuum for $1.5 \mathrm{~h}$. The final volume of echinomycin-in- $\gamma \mathrm{CD}$ inclusion then adjusted to $1 \mathrm{~mL}$ in PBS $\left(\mathrm{pH}\right.$ 7.4) for further loading into liposomes. ${ }^{36}$

To investigate the echinomycin-in- $\gamma \mathrm{CD}$ inclusion complexes, thin layer chromatography (TLC) has been used. TLC was performed on aluminum-backed, $10 \mathrm{~cm} \times 5 \mathrm{~cm}$ silica gel plates. The plates were developed with $n$-hexane $95 \%$, ethylacetate, and methanol $(3: 3: 0.6 \mathrm{v} / \mathrm{v})$ mobile phase. Echinomycin, $\gamma \mathrm{CD}$, echinomycin -in- $\gamma \mathrm{CD}$ and "in situ" mixture were spotted on a baseline,
$0.5 \mathrm{~cm}$ from the edge of the silica plate. The developed plates were air dried, to visualize echinomycin under UV light, and then sprayed with the $5 \%$ ethanolic sulfuric acid solution and dried on a hot plate to locate free and complexed $\gamma$-cyclodextrins.

\subsection{Encapsulation of echinomycin-in- $\gamma \mathrm{CD}$ inclusion into liposomes}

Liposomes loaded with echinomycin-in- $\gamma \mathrm{CD}$ inclusion were prepared by lipid thin-film-hydration method. ${ }^{37}$ A stock solution of lipids composed of DPPC, cholesterol, and DSPE-PEG2000 in a $63: 35: 3$ molar ratio was dissolved in $5 \mathrm{~mL}$ chloroform. The thin-film was formed by evaporation of chloroform using rotary evaporator (IKA, Germany) for $1 \mathrm{~h}$ at $50{ }^{\circ} \mathrm{C}$ under decreased atmospheric pressure using BUCHI® vacuum controller. The
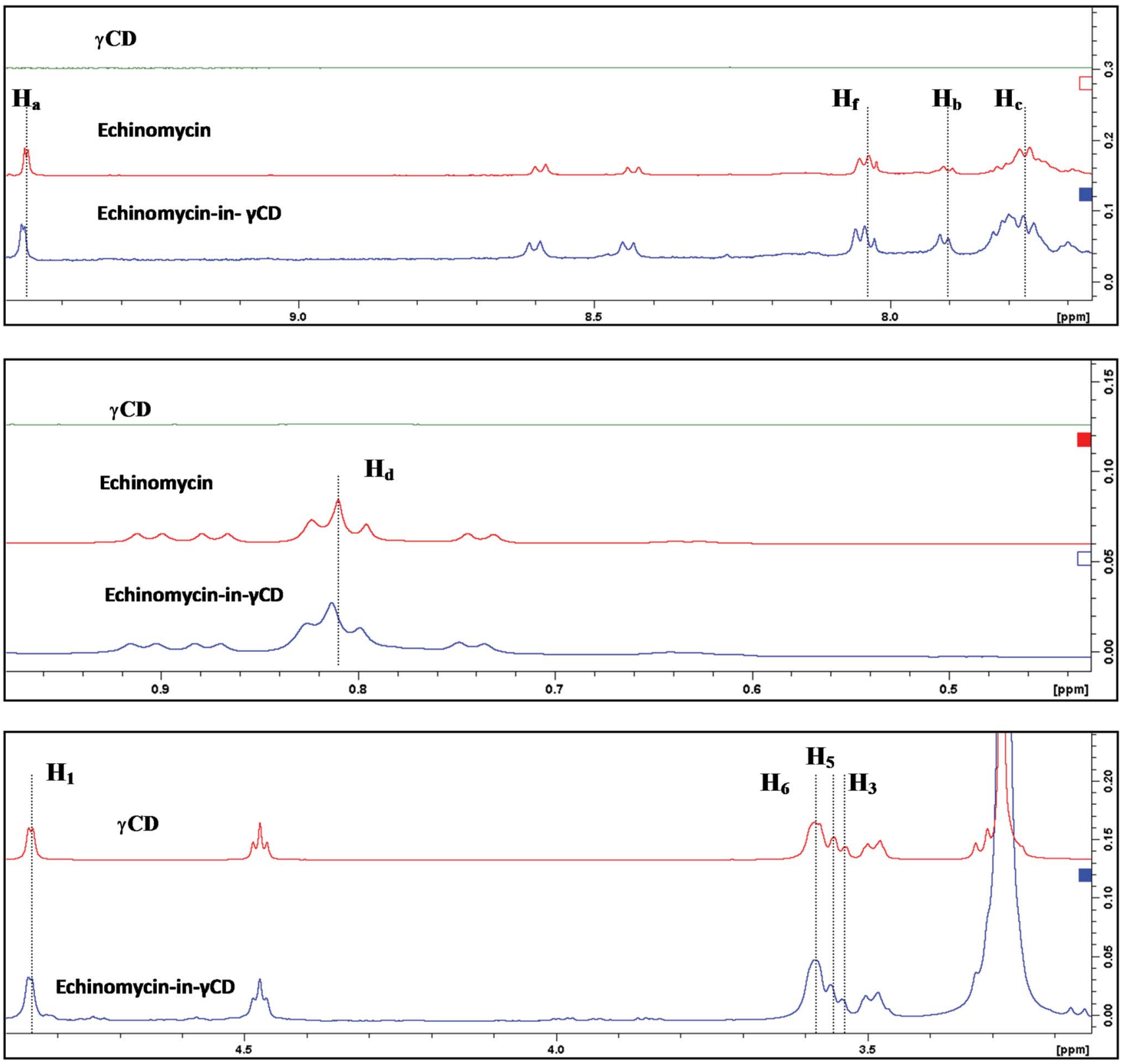

Fig. 3 Inclusion mechanism of echinomycin in $\gamma C D$. ${ }^{1} \mathrm{H}-\mathrm{NMR}$ spectrums for $\gamma C D$, echinomycin and echinomycin-in- $\gamma \mathrm{CD}$ complex in $\mathrm{DMSO}$. 
thin film then was hydrated with echinomycin-in- $\gamma$ CD inclusion, followed by vortex mixing for $30 \mathrm{~min}$ until the thin lipid film was completely dissolved. Downsizing of the hydrated liposomes was performed by extruding the liposomes 13 times through $100 \mathrm{~nm}$ polycarbonate membrane (Nuclepore, Whatman plc, UK) using Mini-Extruder (Avanti Polar Lipids, Inc. USA). After that, the free echinomycin-in- $\gamma \mathrm{CD}$ inclusion was removed by ultrafiltration using Amicon ${ }^{\circledR}$ filters (cut-off of 100 kDa) (Millipore, Germany).

\subsection{Quantification of echinomycin by HPLC}

Quantification of echinomycin was performed by HPLC system (DIONEX TM Ultimate TM 3000, Thermofisher) using reversed phase C18 column $150 \times 4.6 \mathrm{~mm}, 5 \mu \mathrm{m}$ (KNAUER). The mobile phase containing $60 \%$ acetonitrile (HPLC grade) and $40 \%$ water was prepared according to a method described by the National Center for Biotechnology Information (PubChem Database; Echinomycin). Chromatographic conditions were as per the following: the prepared mobile phase was provided in an iso-

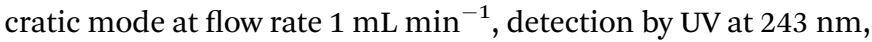
$20 \mu \mathrm{L}$ of each sample was used for injection, the retention time was $4.6 \mathrm{~min}$. The calibration curve was constructed using known concentrations of standard echinomycin in the range $0.000587-0.3 \mathrm{mg} \mathrm{mL}^{-1}$ in absolute ethanol. Echinomycin has been quantified using the linearity regression equation was $Y=$ $1015 X-1.0722$ ( $n=3, r=0.9999)$ (Fig. S2A and B $\dagger$ ). Echinomycin was released from liposomes using acetonitrile up to $1 \mathrm{~mL}$ to disintegrate the liposomes and then quantified by HPLC. The encapsulation efficiency (EE\%) and drug loading (DL\%) were calculated based on the following equation:

$$
\begin{aligned}
& \text { EE }(\%)=(\text { Drug in liposomes/Total drug added }) \times 100 \\
& \text { DL }(\%)=(\text { Weight of loaded drug/Weight of lipids }) \times 100
\end{aligned}
$$

\subsection{Liposomes size and charge}

The mean hydrodynamic diameter of the liposomes was determined by Dynamic Light Scattering (DLS) using a Nano ZS (Malvern Instruments, UK). The polydispersity index (PDI) has been used as an indicator of size distribution. The zeta potential was measured using the same apparatus. All liposomes were diluted in free deionized water to obtain a final sodium chloride concentration of $8 \mathrm{mM}(\mathrm{pH} 7.4)$.

\subsection{Transmission electron microscopy (TEM)}

TEM analysis for blank liposomes and echinomycin-in- $\gamma C D-i n-$ liposomes were performed using the negative staining method. ${ }^{38}$ 200-mesh formvar copper grids (SPI supplies, USA) were uniformly coated with carbon and glow discharged using low vacuum Leica EM ACE200 coating system (Leica, Austria) then coated using 1.5\% vinyl $\mathrm{K}$ solution in chloroform. Further, $7 \mu \mathrm{L}$ of liposomes were placed on the formvar copper grid and left to dry overnight. Next, the loaded grids were stained using 3\% uranyl acetate dye solution. After 20 min, the grids were rinsed with distilled water and air- dried. The prepared grids were observed under Versa 3D (FEI, Netherlands) operated at $30 \mathrm{kV}$.

\subsection{In vitro stability of echinomycin-in- $\gamma$ CD-in-liposomes}

The stability assay of echinomycin-in- $\gamma \mathrm{CD}$-in-liposomes was performed at $4{ }^{\circ} \mathrm{C}$ and $37^{\circ} \mathrm{C}$ in PBS (pH 7.4), with storage times of 14 days. Liposomes samples $(50 \mu \mathrm{L})$ were collected at $4{ }^{\circ} \mathrm{C}$ and $37^{\circ} \mathrm{C}$ at different time intervals $(0,12,24,48,168$, and $336 \mathrm{~h})$. The mean hydrodynamic diameter and polydispersity index (PDI) of echinomycin-in- $\gamma \mathrm{CD}$-in-liposomes were determined at each time point using a similar method described before. All liposomes were diluted in free deionized water to obtain a final sodium chloride concentration of $8 \mathrm{mM}$ ( $\mathrm{pH} 7.4)$.

The release assay of echinomycin from loaded liposomes was performed at $37^{\circ} \mathrm{C}$ in PBS (pH 7.4). Samples of eechinomycinin- $\gamma \mathrm{CD}$-in-liposomes $(700 \mu \mathrm{L})$ were incubated at different times intervals $(0,12,24,48$, and $72 \mathrm{~h})$. The free echinomycin-in- $\gamma \mathrm{CD}$ inclusions at each time point were removed by ultrafiltration using Amicon® filters (cut-off of $100 \mathrm{kDa}$ ) (Millipore, Germany). The concentration of echinomycin in the liposomal fraction was quantified by HPLC using the same method described before. The released echinomycin was calculated based on the initially loaded echinomycin and the remaining echinomycin in liposomes.

\subsection{Echinomycin-cyclodextrin liposomes cellular uptake assessment}

Labeled liposomes were prepared using $0.5 \mathrm{~mol} \%$ of PERhodamine by a thin film hydration method. $5 \times 104$ cells of glioblastoma cell-line U-87 MG were seeded in 12 wells plate (SPL, Korea) containing glass coverslips, and incubated at $37^{\circ} \mathrm{C}$ for 24 hours. After cell attachment and having 50\% confluency, the cells were treated with $20 \mu \mathrm{M}$ of echinomycin-in- $\gamma \mathrm{CD}-\mathrm{PE}-$ Rhodamine complex liposomes and incubated at $37{ }^{\circ} \mathrm{C}$ for $4 \mathrm{~h}$. After incubation, the cells were washed 3 times with $1 \mathrm{~mL}$ of PBS and then fixed by $1 \mathrm{~mL}$ of $4 \%$ formaldehyde for $10 \mathrm{~min}$ at room temperature in dark place. The cells then were washed 3 times using PBS and the coverslips were transferred onto a glass slide and dipped in mounting medium with $4^{\prime}, 6$-diamidino-2-

Table 1 Chemical shifts $(\delta)$ of $\gamma$-CD, echinomycin $\left(\delta_{0}\right)$ and echinomycin-in- $\gamma C D$ complex $\left(\delta_{C}\right)$

\begin{tabular}{lllll}
\hline & Proton & $\delta_{\mathrm{o}}$ & $\delta_{\mathrm{C}}$ & $\Delta \delta$ \\
\hline$\gamma$-CD & $\mathrm{H}_{1}$ & 4.8428 & 4.84423 & 0.00143 \\
& $\mathrm{H}_{2}$ & 3.3086 & 3.3097 & 0.0011 \\
& $\mathrm{H}_{3}$ & 3.5367 & 3.5413 & 0.0046 \\
& $\mathrm{H}_{4}$ & 3.4912 & 3.4939 & 0.0027 \\
& $\mathrm{H}_{5}$ & 3.5547 & 3.5602 & 0.0055 \\
& $\mathrm{H}_{6}$ & 3.5853 & 3.5848 & -0.0005 \\
& $\mathrm{H}_{\mathrm{a}}$ & 9.4594 & 9.4646 & 0.0052 \\
& $\mathrm{H}_{\mathrm{b}}$ & 7.902 & 7.909 & 0.0070 \\
& $\mathrm{H}_{\mathrm{c}}$ & 7.773 & 7.786 & 0.013 \\
& $\mathrm{H}_{\mathrm{d}}$ & 0.8099 & 0.8133 & 0.0034 \\
& $\mathrm{H}_{\mathrm{e}}$ & 3.278 & 3.2803 & 0.0023 \\
& $\mathrm{H}_{\mathrm{f}}$ & 8.037 & 8.044 & 0.0070
\end{tabular}


<smiles>Oc1ccccc1</smiles>

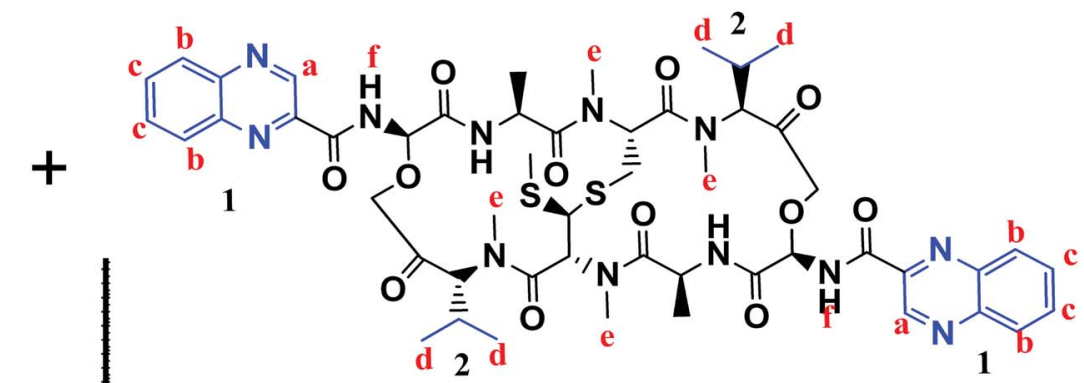

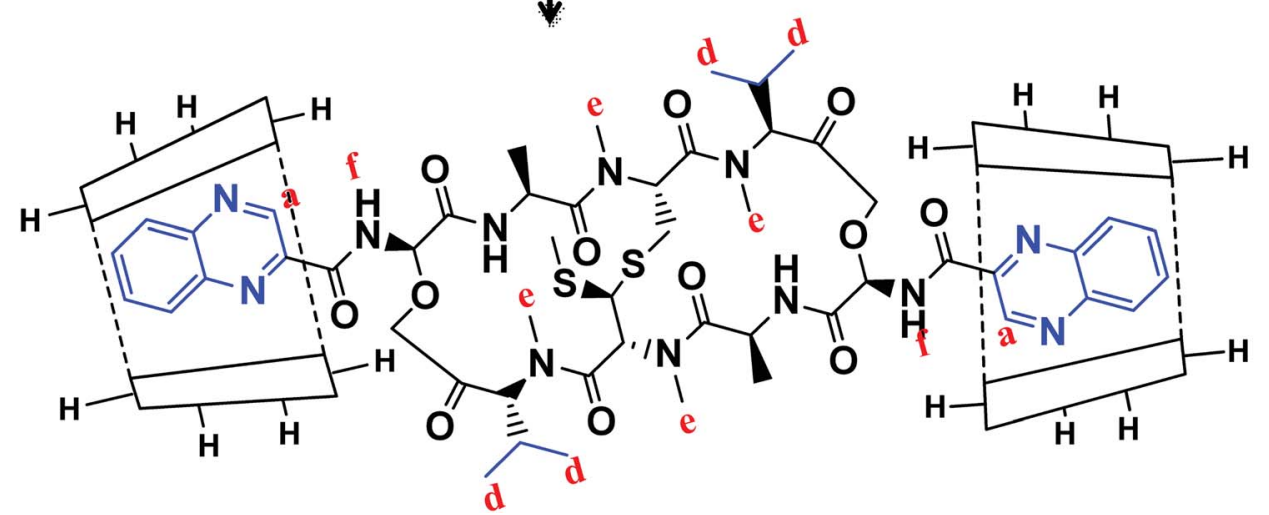

Fig. 4 The proposed model for echinomycin-in- $\gamma C D$ inclusion. Showing the inner and outer cavity hydrogen atoms of $\gamma C D$ and the chemical structure of echinomycin representing the major hydrophobic parts, (1) quinoxaline group and (2) isopropyl group.

phenylindole, dihydrochloride (DAPI), and finally analyzed by confocal microscope system Zeiss LSM780.

\subsection{In vitro cytotoxicity assessment}

U-87 MG cell line was obtained from American Type Culture Collection (ATCC), the cells were cultured in Eagle's Minimum Essential Medium (EMEM) (ATCC, Manassas, USA) supplemented with $10 \%$ fetal bovine serum (Gibco, USA), $1 \% 200 \mathrm{mM}$ L-glutamine, and penicillin-streptomycin (Euroclone, Italy) (100 IU mL ${ }^{-1}$ to $100 \mu \mathrm{g} \mathrm{mL}^{-1}$ ). Cells were kept at $37^{\circ} \mathrm{C}$ in a humidified atmosphere containing $5 \% \mathrm{CO}_{2}$ and subculture was performed at $70-90 \%$ confluency.

The cytotoxicity of free echinomycin and liposomal preparations was determined using cell viability microculture tetrazolium (MTT) assay. Cells were seeded at an initial density of $8 \times 10^{4}$ cells per well in 96-well culture plate (Costar, USA) in $100 \mu \mathrm{L}$ complete culture medium and incubated in a humidified atmosphere of $5 \%$ $\mathrm{CO}_{2}$ at $37{ }^{\circ} \mathrm{C}$ for $24 \mathrm{~h}$. After that, for the U-87 MG cells, a stock solution of free echinomycin, echinomycin-in- $\gamma \mathrm{CD}$ inclusion, echinomycin-in- $\gamma$ CD-in-liposomes were serially diluted in EMEM high glucose medium to reach desired concentrations started from $20 \mathrm{nM}$ to $0.02 \mathrm{nM}$ in $100 \mu \mathrm{L}$ volume and incubated in a humidified atmosphere of $5 \% \mathrm{CO}_{2}$ at $37{ }^{\circ} \mathrm{C}$ for $72 \mathrm{~h}$. The solutions were then removed and replaced with $100 \mu \mathrm{L}$ fresh EMEM and $10 \mu \mathrm{L}$ of MTT solution was added to each well, followed by incubation at $37^{\circ} \mathrm{C}$ for 3 hours. After that, MTT-media solution was removed and 50 $\mu \mathrm{L}$ of DMSO was added to solubilize the dark blue formazan crystals. Absorbance was read at $570 \mathrm{~nm}$ with a microplate reader (Synergy ${ }^{\mathrm{TM}}$ HTX by BioTek Instruments Inc, USA) and the $\mathrm{IC}_{50}$ values were calculated.

\subsection{Invasiveness assay}

Enough collagen with $\mathrm{pH} 7.4$ was pipetted into each chamber of an 8-chamber cover glass (Nunc, Lab-Tek, Thermo scientific). After polymerization at $37^{\circ} \mathrm{C}$ for $45 \mathrm{~min}$, spheroids from hanging drops were carefully removed and 1 spheroid was placed in each chamber of the cover glass. Another $200 \mu \mathrm{L}$ layer of collagen gel matrix was prepared as above and was carefully added to each chamber and then set in a $37^{\circ} \mathrm{C}$ incubator $\left(\right.$ no $\mathrm{CO}_{2}$ ) for $45 \mathrm{~min}$ to polymerize. Finally, $200 \mu \mathrm{L}$ of RPMI was added to each chamber

Table 2 Blank and loaded liposomes characterization

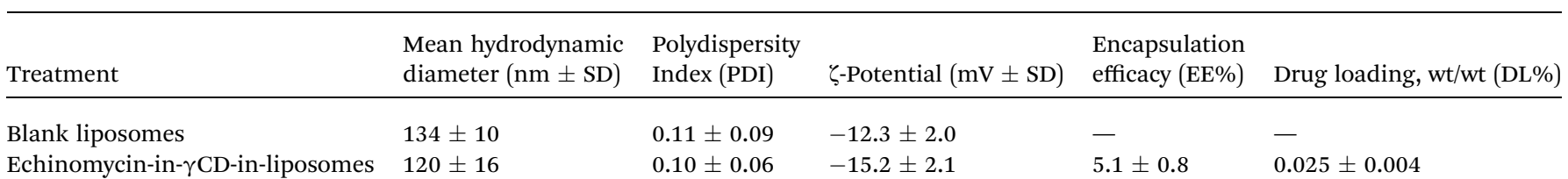


and incubated at $37{ }^{\circ} \mathrm{C}, 5 \% \mathrm{CO}_{2}$ for 4 days. The spheroids were observed using inverted light microscopy at $10 \times$ objective lens and images were captured daily using Nikon Eclipse camera (TE2000-4, Panasonic Lumix DMC-GF6).

\section{Results and discussion}

\subsection{Echinomycin-in- $\gamma$ CD complex formation and characterization}

The poor aqueous solubility is a challenging factor that affects the therapeutic applications of drugs. Most of the anticancer agents belong to class IV of biopharmaceutical classification system which is characterized by the low aqueous solubility and low membrane permeability. ${ }^{39}$ Therefore, different methods have been used to enhance the solubility, dissolution, and bioavailability of water-insoluble drugs such as the use of cosolvents, solubilization, and solid dispersion. ${ }^{\mathbf{4 0}}$ Complexation of drugs with CDs provided an effective approach to enhance the aqueous solubility of poorly soluble drugs thereby improving their therapeutic applications. ${ }^{\mathbf{4 1 - 4 6}}$ Echinomycin is known for the potent antitumor and antimicrobial activity. Interestingly, echinomycin can be intercalated into $5^{\prime}$-CG bases in an irreversible manner which interferes with chemoresistance mechanisms. ${ }^{47-51}$ However, echinomycin is water-insoluble and suffers from low bioavailability and severe side effects. In the current study, echinomycin has been complexed with $\gamma$ CD providing water soluble echinomycin-in$\gamma \mathrm{CD}$ inclusion complexes. The phase solubility diagrams for the complex formation between echinomycin and $\gamma \mathrm{CD}$ showed in Fig. 2A. The plot shows the aqueous solubility of echinomycin increased linearly as the $\gamma \mathrm{CD}$ concentration reaches 60 $\mu \mathrm{M}$. However, the phase solubility diagram showed a negative deviation from the linearity when the $\gamma \mathrm{CD}$ concentrations were above $60 \mu \mathrm{M}$. Therefore, the solubility diagram of echinomycin can be classified as $\mathrm{A}_{\mathrm{N}}$ type according to Higuchi classification. ${ }^{33}$ Several reports have described $A_{N}$ type of solubility diagram and can be explained by the changes to the solvent induced by the solubilizer at different concentrations and/or the self-association of drug molecules, drug/ cyclodextrin inclusion, and formation of non-inclusion complexes. $^{34,52}$ Furthermore, the echinomycin-in- $\gamma \mathrm{CD}$ complexation constant $\left(K_{1: 1}\right)$ was calculated based on the linear part of the phase solubility diagram and was $5.92 \mathrm{mM}^{-1}$, which indicates stable echinomycin-in- $\gamma \mathrm{CD}$ inclusion complexes. Moreover, the binding constant $K_{1: 1}$ was $>1$ which means that the complexation is not a $1: 1$ ratio and can be $1: 2$ or more. This result was anticipated due to the very large size of echinomycin molecule (Fig. 1A). In fact, calculating $S_{0}$ leads to an error due to difficulty in its measurement. In order to avoid $S_{0}$ discrepancy, complexation efficiency(CE) is more convenient to be used. ${ }^{53}$ The solubilizing efficiency (CE) for $1: 1$ echinomycin- $\gamma \mathrm{CD}$ was calculated and found to be 1.8 . It's worth to mention that the less the amount of cyclodextrin being used is better for complexation purposes. According to the value of $\mathrm{CE}$, it can be concluded that a small amount of $\gamma \mathrm{CD}$ is needed to solubilize echinomycin.

A

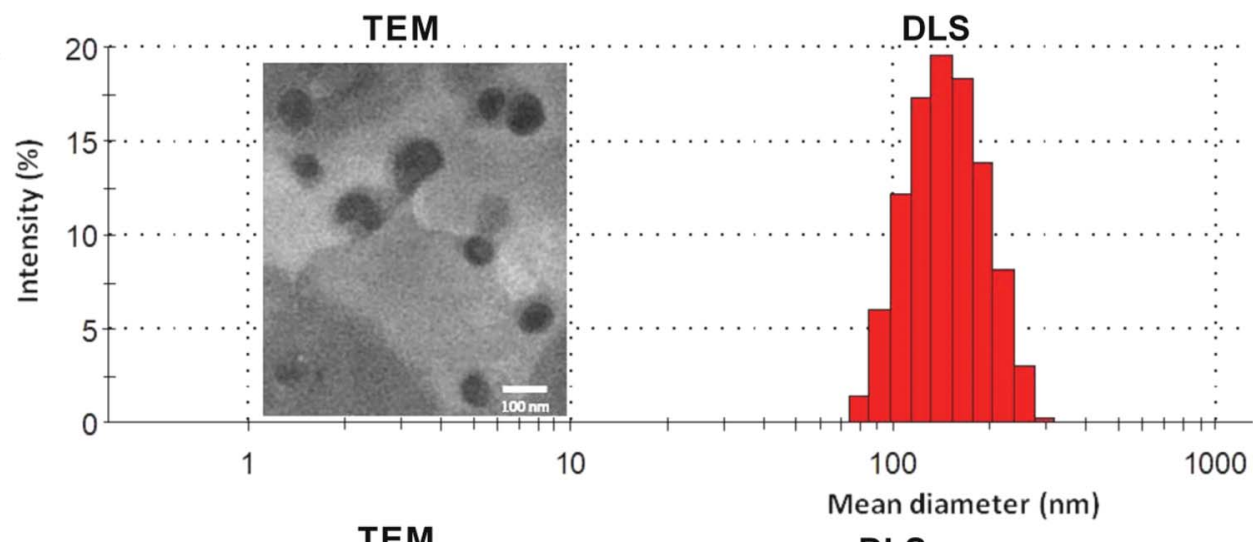

B

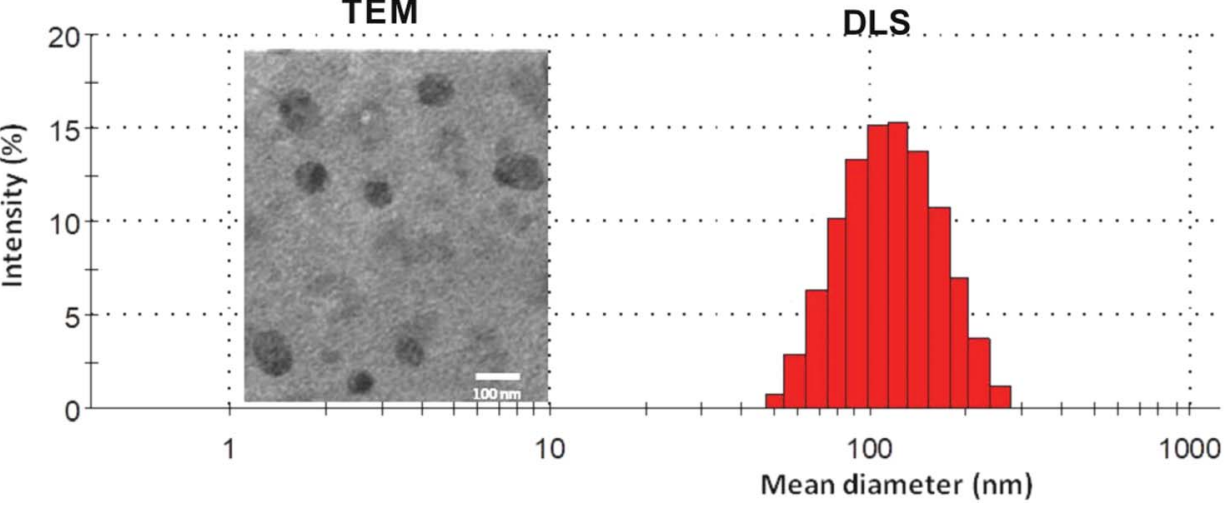

Fig. 5 A representative DLS and TEM graphs of (A) blank liposomes and (B) echinomycin-in- $\gamma$ CD-in-liposomes. 
As concluded from the scanning of echinomycin-in- $\gamma \mathrm{CD}$ complexes using UV visible spectroscopy, Fig. 2B shows a correlation between the enhanced solubility of echinomycin in water with increasing concentrations of $\gamma \mathrm{CD}$ as indicated by the increased absorbance. Actually, due to the small changes in absorbance with increasing $\gamma \mathrm{CD}$ concentration the BenesiHildebrand method was performed. The Benesi-Hildebrand correlation between $1 /[\gamma-\mathrm{CD}]$ and $1 /[\gamma-\mathrm{CD}]^{2}$ vs. $1 /\left(A-A_{0}\right)$ was plotted (Fig. 1D). According to (Fig. 2C and D), the $R^{2}$ of the second-order Benesi $\operatorname{plot}\left(1 /[\gamma-\mathrm{CD}]^{2}\right.$ vs. $\left.1 /\left(A-A_{0}\right)\right)$ is higher than the $R^{2}$ of the first order 0.991 and 0.987 , respectively. This leads us to conclude that the stoichiometry of the inclusion complex is not $1: 1$ and can be $1: 2$ or more. ${ }^{54}$

For further evaluation of echinomycin-in- $\gamma \mathrm{CD}$ inclusion, a thin layer chromatography assay was performed (Fig. S1, ESI $\dagger$ ). Fig. $\mathrm{S} 1 \mathrm{~A} \dagger$ showed different migration rates for non-polar echinomycin, polar $\gamma \mathrm{CD}$ and an in-between spot for echinomycin-in- $\gamma \mathrm{CD}$ complex migration. These observations and the different retention factor $\left(R_{\mathrm{f}}\right)$ values significantly proved the complex formation and the water solubility enhancement of echinomycin upon complexation with $\gamma \mathrm{CD}$. The "in situ" experiment, as shown in Fig. S1B, $\dagger$ exclude the possibility of direct complex formation on the chromatographic plate and indicating the existence of only a physical mixture between echinomycin and $\gamma \mathrm{CD}^{55}$

\subsection{Characterization of the echinomycin-in- $\gamma \mathrm{CD}$ complex by ${ }^{1}$ H-NMR spectroscopy}

${ }^{1} \mathrm{H}-\mathrm{NMR}$ spectra is a useful technique to confirm the formation of an inclusion complex and can provide useful information on the inclusion mechanism of cyclodextrins (CDs) with the guest molecules. Chemical shift changes of specific nuclei in the host molecule can verify the formation of inclusion complex in solution since significant changes in the microenvironment are known to occur in CD of the inclusion complex. ${ }^{56}$ In general, if a guest molecules situated within the cyclodextrin (CD) cavity, then the hydrogen atoms located on the inner shell of the cavity $\left(\mathrm{H}_{3}\right.$ and $\left.\mathrm{H}_{5}\right)$ will be considerably shielded by the guest, while the hydrogen atoms on the outer surface $\left(\mathrm{H}_{1}, \mathrm{H}_{2}, \mathrm{H}_{4}\right)$ will be unaffected by the inclusion complex formation (Fig. 3). The noticeable upfield shift of the protons on the inner cavity of $\gamma \mathrm{CD}$, i.e., $\mathrm{H}_{3}$ and $\mathrm{H}_{5}$ were observed due to shielding by ring current from the aromatic rings of echinomycin (Table 1). The $\mathrm{H}_{1}, \mathrm{H}_{2}$ and $\mathrm{H}_{4}$ protons of $\gamma \mathrm{CD}$, on the outer part of the cavity also encounter a little upfield shift but do not show considerable changes upon addition of echinomycin. The same phenomenon is observed with the $\mathrm{H}_{6}$ proton with a downfield shift. A change of the echinomycin protons environment, when echinomycin enters the hydrophobic cavity of $\gamma \mathrm{CD}$, led to an upfield shift of the $\mathrm{H}_{\mathrm{a}}, \mathrm{H}_{\mathrm{b}}, \mathrm{H}_{\mathrm{c}}$ and $\mathrm{H}_{\mathrm{f}}$ protons of the quinoxaline ring as shown in Fig. 3. There is another inclusion probability from the isopropyl region due to the obvious upfield shift for $\mathrm{H}_{\mathrm{d}}$. The ${ }^{1} \mathrm{H}$ signals for both $\gamma \mathrm{CD}$ and echinomycin molecules could be observed and distinguished in ${ }^{1} \mathrm{H}$ NMR spectrum from echinomycin-in- $\gamma \mathrm{CD}$ inclusion complexes which strongly suggests that the new inclusion complex has been formed as appeared by a model proposed in Fig. 4 .

\subsection{Liposomes preparation and characterization}

In the current work, echinomycin-in- $\gamma \mathrm{CD}$ inclusion has been encapsulated into PEGylated liposomes formulation composed of DPPC : CHOL : DSPE-PEG with $62: 35: 3 \mathrm{~mol} \%$ ratio. The elimination of liposomes from blood circulation is a key issue affecting its therapeutic efficiency. Therefore, PEGylated liposomes (Stealth ${ }^{\circledR}$ liposomes) approached to minimize the interaction with serum proteins and MPS. ${ }^{57}$ Moreover, previous reports have proven that the optimal formulations of PEGylated liposomes contain 3-7 mole $\%$ of PEG-DSPE $2000 .{ }^{58}$ Several properties affect the biological
A

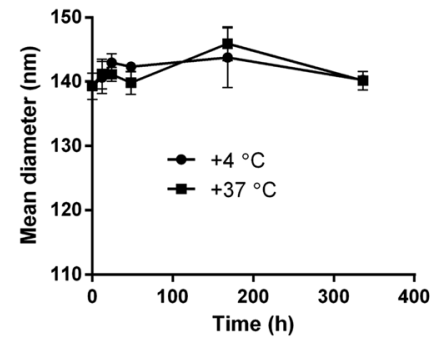

C

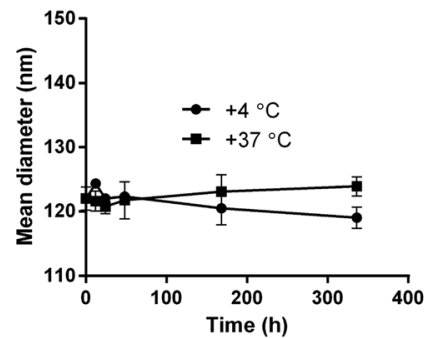

B

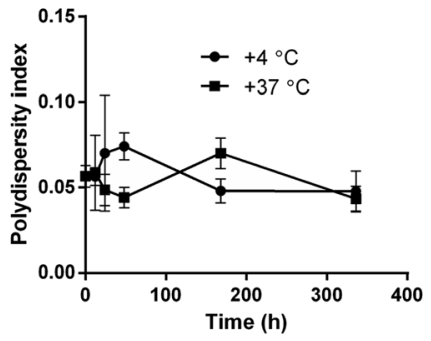

D

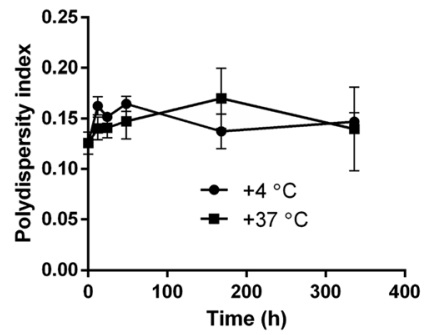

E

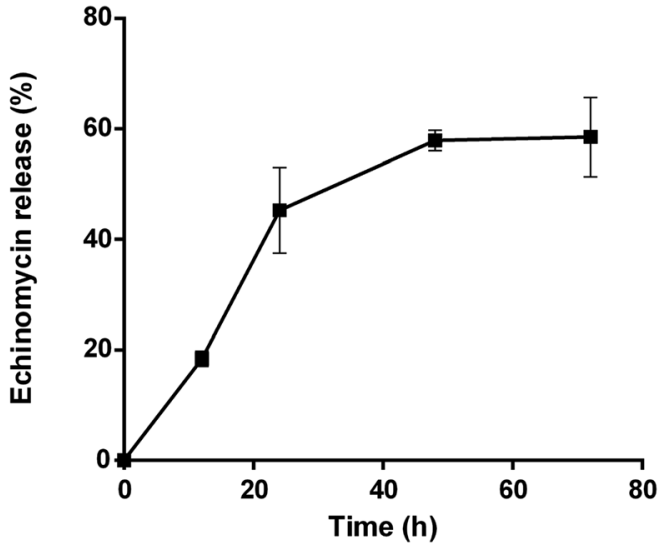

Fig. 6 Colloidal stability of blank liposomes and echinomycin-in- $\gamma \mathrm{CD}$-in-liposomes at $4{ }^{\circ} \mathrm{C}$ and $37^{\circ} \mathrm{C}$. (A) and (B) mean diameter (nm) and the polydispersity index (PDI) of blank liposomes. (C) and (D) mean diameter (nm) and the polydispersity index (PDI) of echinomycin-in- $\gamma C D$-inliposomes. (E) In vitro release of echinomycin from echinomycin-in- $\gamma \mathrm{CD}$-in-liposomes monitored over $72 \mathrm{~h}$ at $37^{\circ} \mathrm{C}$. All values represent the average \pm SD of three independent experiments. 
interactions of liposomes, ${ }^{59}$ the size is one of the decisive parameters, especially for intravenous use. Size between 50-450 nm has an application in the clinical field. ${ }^{60}$ As shown in Table 2, blank liposomes (134 $\pm 10 \mathrm{~nm})$ and echinomycin-in- $\gamma \mathrm{CD}$ loaded liposomes $(120 \pm 16 \mathrm{~nm})$ display no significant differences in the particle sizes. Both liposomes preparations showed similar polydispersity index $(\sim 0.1)$ which demonstrates the presence of a monodisperse distribution. Moreover, the TEM of blank liposomes and echinomycin-in- $\gamma$ CD-in-liposomes formulations revealed that the blank and echinomycin loaded liposomes showed a homogeneous size and spherical shape as shown in Fig. 5A and B. Zeta potential of blank liposomes $(-12 \pm 2 \mathrm{mV})$ showed similar values to the one observed for echinomycin-in- $\gamma \mathrm{CD}$ loaded liposomes $(-15 \pm 2 \mathrm{mV})$. The encapsulation efficiency of echinomycin was found to be around $5.1 \pm 0.8 \%$ (molar ratio) which correspond to a drug loading of $\sim 0.025 \%$ (wt/wt). It worth to mention, the calculated MW of echinomycin-in- $\gamma \mathrm{CD}(1: 2)$ is 3.695 $\mathrm{kDa}$ which may occupy the available spaces and means one out of three encapsulated molecules is echinomycin.

\subsection{In vitro stability and release}

The stability of blank liposomes and echinomycin-in- $\gamma$ CD loaded liposomes were investigated by measuring the changes in the mean size and size distribution (PDI) over a period of 14 days in physiological buffer at $4{ }^{\circ} \mathrm{C}$ (storage temperature) and $37{ }^{\circ} \mathrm{C}$ (physiological temperature). The results showed good stability of both blank and loaded liposomes indicated by minimal changes in the mean size and PDI of blank liposomes and echinomycin-in$\gamma \mathrm{CD}$ loaded liposomes at tested temperatures (Fig. 6A-D). The in vitro release of echinomycin from echinomycin-in- $\gamma \mathrm{CD}$ loaded liposomes was assessed in physiological buffer (PBS, pH 7.4) at
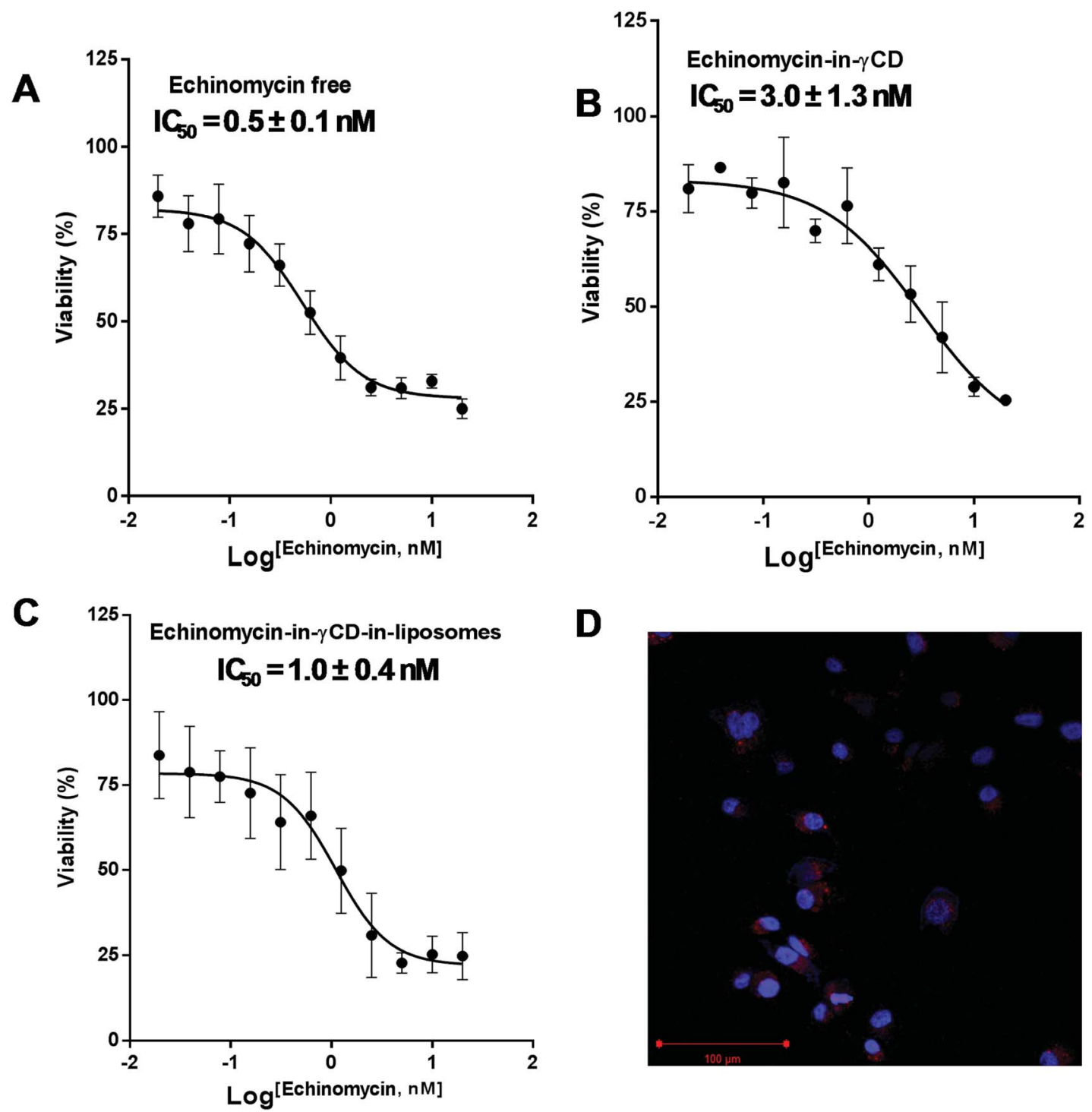

D

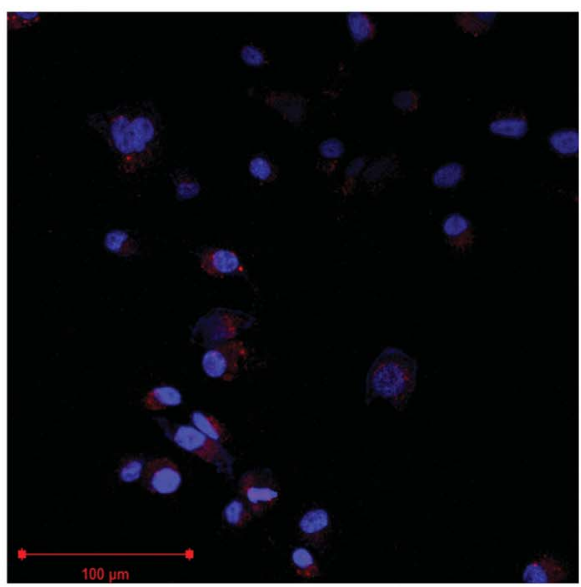

Fig. $7 \quad I C_{50}$ values after treatment with different preparations of echinomycin. (A) The dose-response curve for $U$ - $87 \mathrm{MG}$ cells treated with free echinomycin. (B) The dose-response curve for U-87 MG cells treated with echinomycin-in- $\gamma C D$ inclusion complexes. (C) The dose-response curve for U-87 MG cells treated with echinomycin-in- $\gamma C D$-in-liposomes. (D) Confocal imaging microscopy treated with rhodamine labeled showing the localization of liposomes in the cytoplasm. All cytotoxicity values represent the average \pm SD of three independent experiments. 
$37{ }^{\circ} \mathrm{C}$ over a period of $72 \mathrm{~h}$ at different intervals. The results indicated that echinomycin showed a biphasic release from echinomycin-in- $\gamma \mathrm{CD}$ loaded liposomes (Fig. 6E), with fast release at first $24 \mathrm{~h}(45.2 \%)$ followed by sustained release at $72 \mathrm{~h}(58.5 \%)$. The initial fast release in the biphasic behavior can be explained by the release of echinomycin trapped near liposomes membranes while the sustained release is due to the release of echinomycin trapped deep in the core of liposomes. These findings are in agreement previous studies described that the biphasic release drugs from liposomes. ${ }^{61-63}$

\subsection{Cytotoxicity assessment by MTT}

The cytotoxic activity of free echinomycin, echinomycin-in- $\gamma \mathrm{CD}$, and echinomycin-in- $\gamma \mathrm{CD}$-in-liposomes against U-87 MG cells was evaluated using cell viability assay (MTT) and the $\mathrm{IC}_{50}$ values were calculated. The $\mathrm{IC}_{50}$ values for free echinomycin, echinomycin-in- $\gamma \mathrm{CD}$, and echinomycin-in- $\gamma \mathrm{CD}$-in-liposomes were $0.5 \pm 0.1 \mathrm{nM}, 3.0 \pm 1.3 \mathrm{nM}$, and $1.0 \pm 0.4 \mathrm{nM}$, respectively (Fig. 7A-C). There was no significant toxicity related to blank liposomes. Moreover, the cellular uptake was performed by confocal laser scanning microscopy. Liposomes were
A
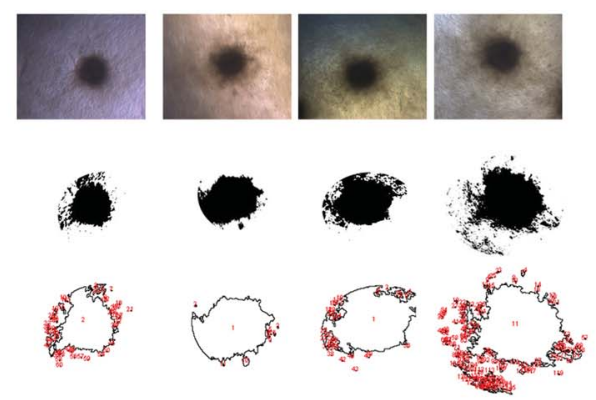

C
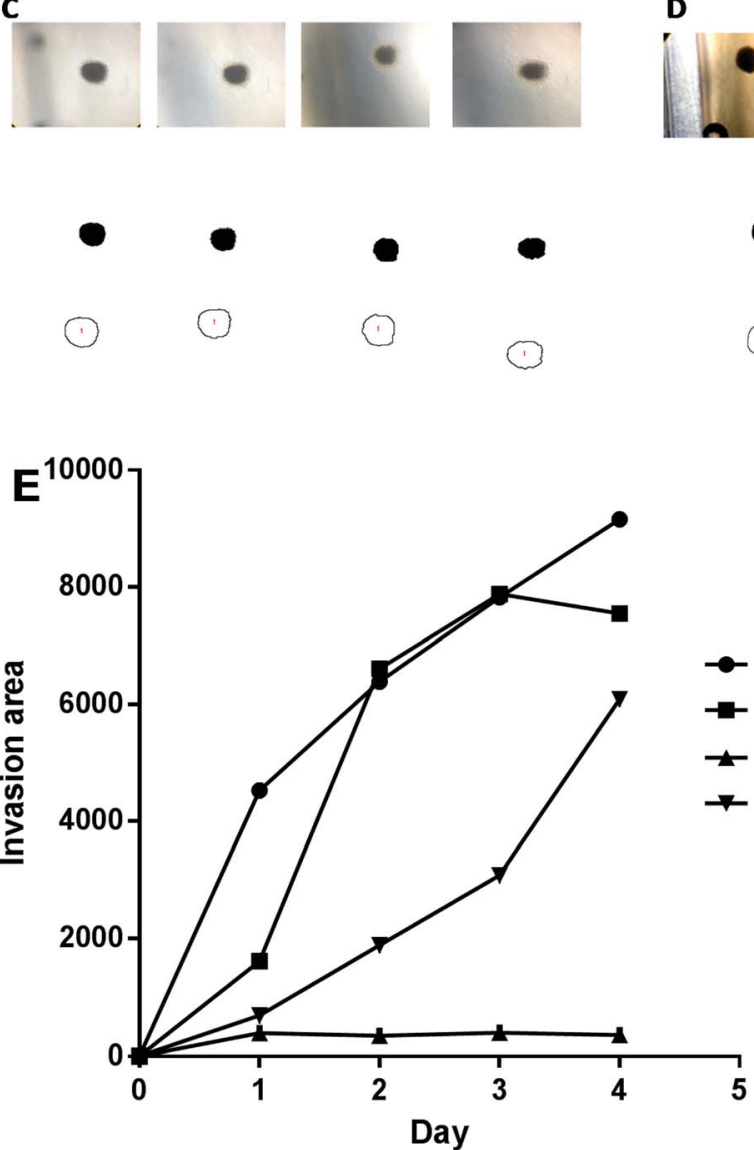

Fig. 8 The spheroid gel invasion assay. The invasion area of U-87 MG spheroids monitored until day 4 after treatment, (A) untreated U-87 MG spheroids, (B) U-87 MG spheroids treated with blank liposomes, (C) U-87 MG spheroids treated with echinomycin-in- $\gamma C D$ inclusion complexes, (D) U-87 MG spheroids treated echinomycin-in- $\gamma C D$-in-liposomes. (E) The average invasion area from day 0 to day 4 . All values represent the average \pm SD of three independent experiments.

\section{。}

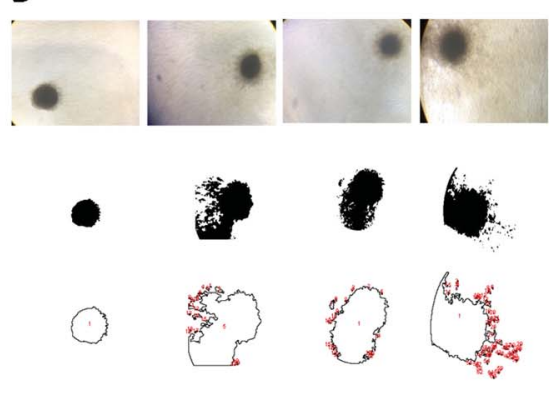

D
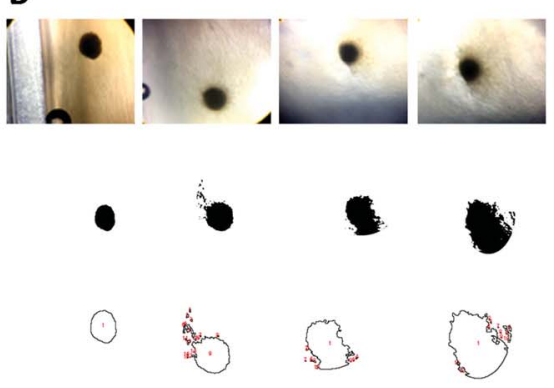

Control cells

- Blank Liposomes

\pm Echinomycin-in- $\gamma \mathrm{CD}$

$\rightarrow$ Echinomycin-in- $\gamma$ CD-in-Liposomes 
fluorescently labeled by grafting of $0.5 \mathrm{~mol} \%$ of with phosphatidylethanolamine Rhodamine-B (PE-Rhodamine). After 4 hours of incubation, liposomes can be seen within the cells, confirming the drug could be available to cells (Fig. 7D). The $\mathrm{IC}_{50}$ value of echinomycin-in- $\gamma \mathrm{CD}$ was $\sim 6$ folds higher compared to the free echinomycin, this can be explained by the fact that the echinomycin can be classified as water-insoluble and membrane permeable. On the other hand, the $\mathrm{IC}_{50}$ value of echinomycin-in- $\gamma$ CD-in-liposomes showed closed cytotoxicity effect compared to free echinomycin. Echinomycin has an extremely potent antitumor effect on different types of cancer cell lines (reviewed in ${ }^{47}$ ). Interestingly, Wang et al. showed that echinomycin can eradicate mouse lymphoma and transplanted human acute myeloid leukemia (AML) in the xenogeneic model by the elimination of cancer stem cells (CSCs). ${ }^{64}$ In a further study, echinomycin showed the ability to protect mice from relapsed AML without effect on hematopoietic stem cells. ${ }^{65}$

\subsection{Invasion assay}

The 3D spheroid gel invasion assay is ideal in providing an indication about the interactions between the tumor cells and tumors microenvironments thereby representing the physiology of avascular solid tumors in vivo. Moreover, glioblastoma is an aggressive type of malignant brain tumors that can invade normal cells of the central nervous system. The spheroid gel invasion assay is characterized by its ability to distinguish invasive cancer cells from non-invasive ones. Therefore, this 3Dculture model is an excellent in vitro model that allow proper interpretation of cellular responses such as invasion to different therapeutics and drug delivery systems in a way that resembles the in vivo environments. ${ }^{66}$

In the current study, spheroid gel invasion assay has been performed to investigate the anti-invasive effect of echinomycin-in- $\gamma$ CD-in-liposomes in comparison with the effect of echinomycin-in- $\gamma$ CD complexes, blank liposomes, and control untreated cells. Collagen type I was used as the matrix in this assay because it is known as the main interstitial matrix component in the solid tumors in vivo. Furthermore, the structural features of collagen that make it able to form gel-like architecture to get more realistic features of the cellular invasion process and making this assay more able to mimic the in vivo situation. ${ }^{67,68}$ Fig. 8 shows that free echinomycin-in- $\gamma \mathrm{CD}$ inclusion complexes echinomycin-in- $\gamma \mathrm{CD}$-in-liposomes was found to reduce the invasion of the U-87 MG spheroids in a time-dependent manner compared to the control and the blank liposomes treated spheroids. The echinomycin-in- $\gamma \mathrm{CD}-$ in-liposomes was less able to reduce the invasion of the U-87 MG spheroids compared to the echinomycin-in- $\gamma$ CD inclusion complexes (Fig. 6E). This is likely related to the size of liposomes that cannot penetrate easily into the inner layers of the spheroids compared to the echinomycin-in- $\gamma \mathrm{CD}$ inclusion complexes. The concentration of the echinomycin used was selected based on the $\mathrm{IC}_{50}$ values that were calculated through the MTT chemosensitivity assay. The 3D invasion assay is ideal in maintaining the structural and morphological properties of the cells in the spheres allowing real-time monitoring of the basic features of the cellular invasion during the running time of the assay. The invasive cells started to invade out from the embedded spheroids into the surrounding collagen as early as the first day after embedding. However, the non-invasive cancer cells grow as compact spheroids with clear borders from the surrounding matrix, with no signs of invasion even after 7 days of culture.

\section{Conclusions}

In this work, we show for the first time the complexation of echinomycin with $\gamma C D$ (echinomycin-in- $\gamma C D$ ) and the loading into PEGylated liposomes (echinomycin-in- $\gamma$ CD-in-liposomes). The liposomes encapsulating echinomycin showed potent anti-proliferative and anti-invasive effect against U-87 MG glioblastoma cell line. Glioblastoma is an aggressive type of malignant brain tumors with less than $5 \%$ of patient survival after 5 years of diagnosis. The available therapies don't bear a higher survival rate in GBM patients due to the aggressive nature of glioblastoma that can invade normal cells of the central nervous system and the protection advantage by the neurovascular niche. Further animal studies should confirm the advantage of using the echinomycin-in- $\gamma \mathrm{CD}$-in-liposomes formulation as a promising alternative for the treatment of glioblastoma.

\section{Contributions}

M. Z., A. A., H. N., Z. L., D. A., E. A., T. A., A. A., S. W. carried out all experiments, data curation, software, and writing-original draft. W. A., M. Z., M. Z., and F. O. contributed to data investigation and writing-original draft. A. A., Y. B., and E. F. contributed to supervision, validation, and review-editing. W. A. contributed to conceptualization, methodology, investigation, project administration, data validation, and writing-original draft.

\section{Conflicts of interest}

There are no conflicts to declare.

\section{Acknowledgements}

The authors would like to the thank Hamdi Mango Center for Scientific Research, The University of Jordan (Grant\#4200053). Scientific Research Fund (Grant\#MPH/2/8/2013). We also would like to thank Ms Hanan Azzam and Ms Rula Buqaien (The University of Jordan) for assistance on HPLC and TEM, respectively.

\section{References}

1 J. A. Cuesta-Seijo and G. M. Sheldrick, Acta Crystallogr., Sect. D: Biol. Crystallogr., 2005, 61, 442-448.

2 B. J. Foster, K. Clagett-Carr, D. D. Shoemaker, M. Suffness, J. Plowman, L. A. Trissel, C. K. Grieshaber and B. LeylandJones, Invest. New Drugs, 1985, 3, 403-410. 
3 K. Katagiri, T. Yoshida and K. Sato, in Mechanism of action of antimicrobial and antitumor agents, Springer, 1975, pp. 234251.

4 L. G. May, M. A. Madine and M. J. Waring, Nucleic Acids Res., 2004, 32, 65-72.

5 J. Yamaguchi, T. Tanaka, H. Saito, S. Nomura, H. Aburatani, H. Waki, T. Kadowaki and M. Nangaku, Sci. Rep., 2017, 7, 6516.

6 Y. Wang, Y. Liu, F. Tang, K. M. Bernot, R. Schore, G. Marcucci, M. A. Caligiuri, P. Zheng and Y. Liu, Blood, 2014, 124, 1127-1135.

7 D. Kong, E. J. Park, A. G. Stephen, M. Calvani, J. H. Cardellina, A. Monks, R. J. Fisher, R. H. Shoemaker and G. Melillo, Cancer Res., 2005, 65, 9047-9055.

8 P.-C. Wu, S.-L. Tzeng, C.-K. Chang, Y.-F. Kao, M. J. Waring and M.-H. Hou, Nucleic Acids Res., 2018, 46, 7396-7404.

9 A. Y. Chang, K. Kim, H. Boucher, P. Bonomi, J. A. Stewart, D. D. Karp and R. H. Blum, Cancer, 1998, 82, 292-300.

10 W. J. Gradishar, N. J. Vogelzang, L. J. Kilton, S. J. Leibach, A. W. Rademaker, S. French and A. B. Benson 3rd, Invest. New Drugs, 1995, 13, 171-174.

11 W. J. Gradishar, N. J. Vogelzang, L. J. Kilton, S. J. Leibach, A. W. Rademaker, S. French and A. B. Benson, Invest. New Drugs, 1995, 13, 171-174.

12 S. Wadler, L. Tenteromano, L. Cazenave, J. A. Sparano, E. S. Greenwald, A. Rozenblit, R. Kaleya and P. H. Wiernik, Cancer Chemother. Pharmacol., 1994, 34, 266-269.

13 D. H. Shevrin, T. E. Lad, P. Guinan, L. J. Kilton, A. Greenburg, P. Johnson, R. R. Blough and H. Hoyer, Invest. New Drugs, 1994, 12, 65-66.

14 A. Y. Chang, Z. N. Tu, G. T. Bryan, J. M. Kirkwood, M. M. Oken and D. L. Trump, Invest. New Drugs, 1994, 12, 151-153.

15 H. B. Muss, J. A. Blessing and B. DuBeshter, Am. J. Clin. Oncol., 1993, 16, 492-493.

16 M. E. Marshall, M. K. Wolf, E. D. Crawford, S. Taylor, B. Blumenstein, R. Flanigan, F. J. Meyers, H. E. Hynes, B. Barlogie and M. Eisenberger, Invest. New Drugs, 1993, 11, 207-209.

17 S. A. Taylor, J. Crowley, J. Townsend, F. S. Vogel, H. Eyre, J. J. Braun and J. W. Goodwin, J. Neuro-Oncol., 1993, 15, 181-184.

18 H. B. Muss, J. A. Blessing, P. Hanjani, J. H. Malfetano, G. M. Kemp and K. Webster, Am. J. Clin. Oncol., 1992, 15, 363-364.

19 H. B. Muss, J. A. Blessing, G. L. Eddy and R. McGehee, Invest. New Drugs, 1992, 10, 25-26.

20 R. L. Schilsky, D. Faraggi, A. Korzun, N. Vogelzang, J. Ellerton, W. Wood and I. C. Henderson, Invest. New Drugs, 1991, 9, 269-272.

21 J. G. Kuhn, D. D. Von Hoff, M. Hersh, T. Melink, G. M. Clark, G. R. Weiss and C. A. Coltman, Eur. J. Cancer Clin. Oncol., 1989, 25, 797-803.

22 M. E. Davis, Clin. J. Oncol. Nurs., 2016, 20, S2.

23 F. Hanif, K. Muzaffar, K. Perveen, S. M. Malhi and S. U. Simjee, Asian Pac. J. Cancer Prev., 2017, 18, 3.

24 S. Y. Lee, Genes Dis., 2016, 3, 198-210.
25 Z. Huang, L. Cheng, O. A. Guryanova, Q. Wu and S. Bao, Protein Cell, 2010, 1, 638-655.

26 J. Shi, P. W. Kantoff, R. Wooster and O. C. Farokhzad, Nat. Rev. Cancer, 2017, 17, 20.

27 A. Wicki, D. Witzigmann, V. Balasubramanian and J. Huwyler, J. Controlled Release, 2015, 200, 138-157.

28 U. Bulbake, S. Doppalapudi, N. Kommineni and W. Khan, Pharmaceutics, 2017, 9, 12.

29 M. Voinea and M. Simionescu, J. Cell. Mol. Med., 2002, 6, 465-474.

30 S. Tran, P.-J. DeGiovanni, B. Piel and P. Rai, Clin. Transl. Med., 2017, 6, 44.

31 G. Bangale, K. Rajesh and G. Shinde, Int. J. Pharma Sci. Res., 2014, 5, 750-759.

32 B. Gidwani and A. Vyas, BioMed Res. Int., 2015, 2015, 198268. 33 T. Higuchi, Adv. Anal. Chem. Instrum., 1965, 4, 117-211.

34 T. Loftsson, D. Hreinsdottir and M. Masson, Int. J. Pharm., 2005, 302, 18-28.

35 S. Sur, A. C. Fries, K. W. Kinzler, S. Zhou and B. Vogelstein, Proc. Natl. Acad. Sci. U. S. A., 2014, 111, 2283-2288.

36 V. Chaudhary and J. Patel, Int. J. Pharma Sci. Res., 2013, 4, 6876.

37 A. D. Bangham and R. W. Horne, J. Mol. Biol., 1964, 8, 660. 38 M. Placzek and M. Kosela, Acta Pharm., 2016, 66, 1-22.

39 G. L. Amidon, H. Lennernäs, V. P. Shah and J. R. Crison, Pharm. Res., 1995, 12, 413-420.

40 B. Gidwani and A. Vyas, BioMed Res. Int., 2015, 2015, 198268. 41 A. Lodagekar, R. M. Borkar, S. Thatikonda, R. B. Chavan, V. G. M. Naidu, N. R. Shastri, R. Srinivas and N. Chella, Carbohydr. Polym., 2019, 212, 252-259.

42 N. Li, N. Wang, T. Wu, C. Qiu, X. Wang, S. Jiang, Z. Zhang, T. Liu, C. Wei and T. Wang, Drug Dev. Ind. Pharm., 2018, 44, 1966-1974.

43 P. Saokham, C. Muankaew, P. Jansook and T. Loftsson, Molecules, 2018, 23, 1161.

44 L. Kai-Hang, S. Mengying, T. Guping and H. U. Xiurong, Zhejiang Daxue Xuebao, Yixueban, 2017, 46, 151-159.

45 A. R. Prado, F. Yokaichiya, M. Franco, C. Silva, L. OliveiraNascimento, M. Franz-Montan, M. C. Volpato, L. F. Cabeca and E. de Paula, J. Pharm. Pharmacol., 2017, 69, 652-662.

46 S. Charumanee, S. Okonogi, J. Sirithunyalug, P. Wolschann and H. Viernstein, Sci. Pharm., 2016, 84, 694-704.

47 Y.-S. Park, W.-S. Shin, C.-S. Kim, C. M. Ahn, X.-F. Qi and S.-K. Kim, Mol. Cell. Toxicol., 2018, 14, 9-18.

48 R. Pfoh, J. A. Cuesta-Seijo and G. M. Sheldrick, Acta Crystallogr., Sect. F: Struct. Biol. Cryst. Commun., 2009, 65, 660-664.

49 A. M. Socha, K. L. Laplante, D. J. Russell and D. C. Rowley, Bioorg. Med. Chem. Lett., 2009, 19, 1504-1507.

50 Y. S. Park, W. S. Shin and S. K. Kim, J. Antimicrob. Chemother., 2008, 61, 163-168.

51 J. A. Cuesta-Seijo and G. M. Sheldrick, Acta Crystallogr., Sect. D: Biol. Crystallogr., 2005, 61, 442-448.

52 T. Mihajlovic, K. Kachrimanis, A. Graovac, Z. Djuric and S. Ibric, AAPS PharmSciTech, 2012, 13, 623-631.

53 P. Jansook and T. Loftsson, Int. J. Pharm., 2008, 363, 217219. 
54 K. Srinivasan, T. Stalin and K. Sivakumar, Spectrochim. Acta, Part A, 2012, 94, 89-100.

55 L. Sbârcea, L. Udrescu, L. Drăgan, C. Trandafirescu, Z. Szabadai and M. Bojiţă, Farmacia, 2010, 58, 478-484.

56 B. Cwiertnia, T. Hladon and M. Stobiecki, J. Pharm. Pharmacol., 1999, 51, 1213-1218.

57 W. Zhao and X.-R. Q. Song Zhuang, Int. J. Nanomed., 2011, 6, 3087.

58 S. Zalipsky, J. Gittelman, N. Mullah, M. M. Qazen and J. A. Harding, in Targeting of Drugs 6, Springer, 1998, pp. 131-138.

59 B. Sabeti, M. I. Noordin, S. Mohd, R. Hashim, A. Dahlan and H. Akbari Javar, BioMed Res. Int., 2014, 2014, 765426.

60 G. Bozzuto and A. Molinari, Int. J. Nanomed., 2015, 10, 975.

61 L. R. Tefas, B. Sylvester, I. Tomuta, A. Sesarman, E. Licarete, M. Banciu and A. Porfire, Drug Des., Dev. Ther., 2017, 11, 1605-1621.
62 T. Yang, F. D. Cui, M. K. Choi, J. W. Cho, S. J. Chung, C. K. Shim and D. D. Kim, Int. J. Pharm., 2007, 338, 317-326.

63 P. Panwar, B. Pandey, P. C. Lakhera and K. P. Singh, Int. J. Nanomed., 2010, 5, 101-108.

64 Y. Wang, Y. Liu, S. N. Malek, P. Zheng and Y. Liu, Cell Stem Cell, 2011, 8, 399-411.

65 Y. Wang, Y. Liu, F. Tang, K. M. Bernot, R. Schore, G. Marcucci, M. A. Caligiuri, P. Zheng and Y. Liu, Blood, 2014, 124, 1127-1135.

66 R. Edmondson, J. J. Broglie, A. F. Adcock and L. Yang, Assay Drug Dev. Technol., 2014, 12, 207-218.

67 F. Bruyere, L. Melen-Lamalle, S. Blacher, G. Roland, M. Thiry, L. Moons, F. Frankenne, P. Carmeliet, K. Alitalo, C. Libert, J. P. Sleeman, J. M. Foidart and A. Noel, Nat. Methods, 2008, 5, 431-437.

68 F. Sabeh, R. Shimizu-Hirota and S. J. Weiss, J. Cell Biol., 2009, 185, 11-19. 